\title{
Tandem affinity purification combined with inducible shRNA expression as a tool to study the maturation of macromolecular assemblies
}

\author{
EMANUEL WYLER, ${ }^{1,2}$ MIRJAM ZIMMERMANN, ${ }^{1}$ BARBARA WIDMANN,${ }^{1,2}$ MATTHIAS GSTAIGER, ${ }^{3}$ \\ JENS PFANNSTIEL, ${ }^{4}$ ULRIKE KUTAY, ${ }^{1}$ and IVO ZEMP ${ }^{1}$ \\ ${ }^{1}$ Institute of Biochemistry, ETH Zurich, $\mathrm{CH}-8093$ Zurich, Switzerland \\ ${ }^{2}$ Molecular Life Science PhD Program, Zurich, Switzerland \\ ${ }^{3}$ Institute of Molecular Systems Biology, ETH Zurich, CH-8093 Zurich, Switzerland \\ ${ }^{4}$ Life Science Center and Institute of Physiology, University Hohenheim, D-70599 Hohenheim, Germany
}

\begin{abstract}
Tandem affinity purification (TAP) is an efficient method for the purification and characterization of large macromolecular complexes. To elucidate the role of specific components of such complexes, it is important to address the question of how loss of a specific factor affects complex composition. Here, we introduce a method that combines TAP of large macromolecular assemblies with inducible shRNA-mediated protein depletion in human somatic cells. As a proof of principle, we have applied this method to the purification of human pre-ribosomal particles. Using inducible expression of ribosome assembly factors as bait proteins, different pre-40S particles could be isolated and characterized, revealing high conservation of the ribosome biogenesis pathway from yeast to human cells. Besides known ribosome maturation factors, $\mathrm{C} 21$ orf70 was identified as a novel pre-40S component. By combining TAP of pre-40S particles with shRNA-mediated depletion of the pre-40S-associated protein kinase Rio2, we observed that increased levels of the nuclear HEAT-repeat protein Rrp12 are associated with $40 \mathrm{~S}$ precursors in absence of Rio2. Further analyses revealed that Rrp12 is partially mislocalized to the cytoplasm and trapped on late 40S precursors upon loss of Rio2, and therefore fails to efficiently recycle to the nucleus. Thus, the combination of tandem affinity purification and shRNA induction provided further insights into late cytoplasmic $40 \mathrm{~S}$ maturation steps, demonstrating the high potential of this method.
\end{abstract}

Keywords: ribosome biogenesis; tandem affinity purification; 40S subunit; Rio2 kinase; Rrp12; C21orf70

\section{INTRODUCTION}

The development of tandem affinity purification (TAP) procedures has greatly facilitated the purification and characterization of native protein complexes. After being established in Saccharomyces cerevisiae (Rigaut et al. 1999), similar protocols have also been developed for cultured somatic cells (Forler et al. 2003; Glatter et al. 2009). One research field that has greatly profited from these new technologies is eukaryotic ribosome biogenesis. Using TAP in yeast, pre-

Abbreviations: TAP, tandem affinity purification; shRNA, small hairpin RNA; HEAT, Huntingtin, elongation factor 3, protein phosphatase 2A, PI3-kinase TOR; RNAi, RNA interference; HASt-TAP or StHA-TAP, hemagglutinin-streptavidin TAP; MS, mass spectrometry; ESI, electrospray ionization; WT, wild-type; KD, kinase-dead.

Reprint requests to: Ulrike Kutay, Institute of Biochemistry, ETH Zurich, Schafmattstrasse 18 HPM F11.1, CH-8093 Zurich, Switzerland; e-mail: ulrike.kutay@bc.biol.ethz.ch; fax: 41-44-633 1449.

Article published online ahead of print. Article and publication date are at http://www.rnajournal.org/cgi/doi/10.1261/rna.2325911. ribosomal particles could be isolated and characterized (Bassler et al. 2001; Harnpicharnchai et al. 2001; Saveanu et al. 2001; Dragon et al. 2002; Fatica et al. 2002; Gavin et al. 2002; Grandi et al. 2002; Ho et al. 2002; Nissan et al. 2002; Schafer et al. 2003), which has led to an improved understanding of ribosomal subunit assembly and to a description of the ribosome biogenesis pathway (for review, see Fromont-Racine et al. 2003; Tschochner and Hurt 2003).

Eukaryotic ribosome synthesis starts in nucleoli with the transcription of precursor rRNA (pre-rRNA), from which the mature rRNA sequences have to be excised. Pre-rRNA, ribosomal proteins, and additional, so-called trans-acting factors are assembled into an early, 90S-sized ribosomal precursor (Dragon et al. 2002; Grandi et al. 2002). This precursor is matured by endo- and exonucleolytic processing of the pre-rRNA to mature rRNA, accompanied by dynamic changes in the protein composition of the particle. Endonucleolytic cleavage separates the $90 \mathrm{~S}$ pre-ribosome into pre$60 \mathrm{~S}$ and pre-40S particles, which undergo nucleolar and 
nucleoplasmic maturation steps before they are exported to the cytoplasm. Final cytoplasmic maturation includes additional pre-rRNA processing steps and the removal of all remaining trans-acting factors from both precursors, allowing $40 \mathrm{~S}$ and $60 \mathrm{~S}$ subunits to reach translation competence (Zemp and Kutay 2007; Henras et al. 2008).

Whereas a series of yeast pre- $40 \mathrm{~S}$ and pre-60S particles have been characterized by employing TAP, only few pre-ribosomal particles have been isolated from human cells, mainly by immunoprecipitation of overexpressed epitope-tagged factors (Yanagida et al. 2001; Fujiyama et al. 2002; Hayano et al. 2003). Recently, we reported the isolation of a late $40 \mathrm{~S}$ subunit precursor associated with Rio2, a protein kinase involved in nuclear export of $40 \mathrm{~S}$ precursors and required for cytoplasmic recycling steps of $40 \mathrm{~S}$ trans-acting factors (Zemp et al. 2009). This particle was isolated by immunoprecipitation of the endogenous protein from fractionated cell extracts. However, such purification is time-consuming, requires high amounts of input material, and is dependent on the availability of a suitable antibody. Moreover, to study the molecular function of specific trans-acting factors in ribosome biogenesis, it is desirable to determine how particle composition and structure is affected after loss of a factor of interest.

In this study, we present the application of tandem affinity purification to the isolation and characterization of human ribosomal subunit precursors. We established a series of stably transfected HEK 293 cell lines allowing for the inducible expression of bait proteins bearing tandem hemagglutinin-streptavidin tags (HASt-TAP tags) to purify late 40 S subunit precursors by TAP. To perform TAP after the depletion of a certain factor by RNA interference (RNAi), we extended this method by using the tetracycline-inducible expression of small hairpin RNAs (shRNAs) targeting this very factor. For proof of concept, we combined TAP purification of the late $40 \mathrm{~S}$ trans-acting factor Ltv1 with the inducible knockdown of Rio2. The analysis of particle composition revealed that although pre-40S composition was not strongly altered by the absence of Rio2, increased levels of Rrp12 were associated with late pre-40S particles. These results were confirmed in HeLaK cells using a classical immunoprecipitation approach. To address the biological significance of this finding, we performed immunofluorescence analysis of Rrp12 upon Rio2 depletion and observed that Rrp12 was partially mislocalized to the cytoplasm after Rio2 knockdown. Together, our data show that Rio2 is required for release of Rrp12 from $40 \mathrm{~S}$ precursors in the cytoplasm.

\section{RESULTS}

\section{Characterization of human $40 S$ subunit precursors purified by tandem affinity purification}

To purify and characterize human pre-ribosomes, we used a recently described double affinity tag consisting of a hem- agglutinin epitope tag and a streptavidin-binding peptide (N-terminal HASt-TAP-tag or C-terminal StHA-TAP-tag) (Fig. 1A; Glatter et al. 2009). Based on data from yeast (Milkereit et al. 2003; Schafer et al. 2003) and on previous results using immunoprecipitation of human $40 \mathrm{~S}$ precursors (Zemp et al. 2009), several bait proteins were chosen to isolate 40S subunit precursor particles: Noc4, Dim1, Enp1/ BYSL, Dim2/PNO1, and Ltv1. First, we confirmed that the fusion with the HASt-TAP-tag did not alter the steady-state localization of the chosen trans-acting factors in HeLaK cells (Fig. 1B). Enp1-StHA and HASt-Dim2 are predominantly nucleolar proteins, while HASt-tagged Ltv1 is localized to the cytoplasm, corresponding to the localization of the respective endogenous proteins as previously observed (Zemp et al. 2009). Endogenous Noc4 and Dim1 are predominantly localized to nucleoli, as previously described for their yeast counterparts Noc4p (Milkereit et al. 2003) and Dimlp (Lafontaine et al. 1998; Schafer et al. 2003). HASt-Noc4 and HASt-Dim1 display the same localization as the endogenous proteins, again indicating that the presence of the HASt-tag does not affect the steady-state localization of these proteins. Using the FlpIn TRex system (Invitrogen), we then established a series of HEK 293 cell lines in which expression of the HASt-TAP-tagged bait proteins can be induced by the addition of tetracycline (Fig. 1C).

To determine whether the HASt-TAP-tagged proteins are associated with $40 \mathrm{~S}$ subunit precursors, we performed sucrose gradient sedimentation analysis of extracts of untransfected and HASt-TAP expressing cells (Fig. 1D). Western blot analysis for Enp1-StHA-TAP-expressing cells revealed that Enp1-StHA-TAP partially co-sedimented with $40 \mathrm{~S}$ precursors, indicating that it is incorporated into pre-40S particles. An additional pool of Enp1-StHA-TAP was detected at the top of the gradient. Likewise, endogenous Enp1 is both found in the $40 \mathrm{~S}$ fractions and at the top of the gradient, in untransfected as well as in Enp1-StHA-TAP-expressing cells. Compared to untransfected cells, endogenous Enp1 was slightly shifted to the free protein fractions in Enp1StHA-TAP-expressing cells, suggesting that endogenous and StHA-TAP-tagged Enp1 compete for binding sites on $40 \mathrm{~S}$ precursors. Similarly, incorporation into ribosomal particles was also observed for the bait proteins Ltv1, Dim1, and Dim2, whereas Noc4, a component of early pre-ribosomes in yeast, was mostly present in the top fractions of the gradient (Fig. 1D).

Before performing tandem affinity purification of HAStTAP-tagged factors, we first analyzed our extract preparation method by Western blotting for several proteins involved in $40 \mathrm{~S}$ subunit synthesis (Fig. 2A). As expected, the cytoplasmic protein Ltv1 was almost completely extracted. Whereas the nucleolar protein Fibrillarin was absent from the extract, several other predominantly or almost exclusively nucleolar proteins like Nucleolin, Dim2, or Enp1 were partially extracted. These results indicate that parts of nucleoli are extracted in the presence of $0.5 \%$ NP-40. Thus, 
A

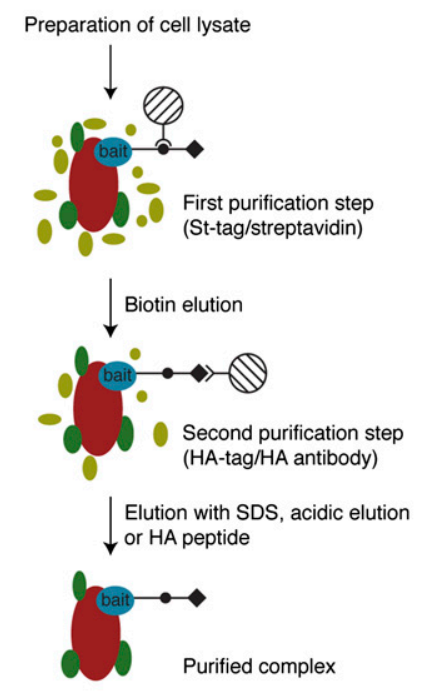

C

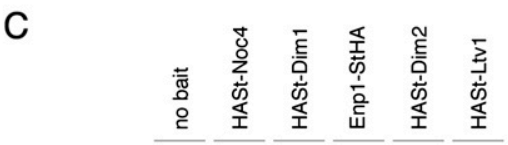

-

Noc4

Dim1

Enp1

Dim2

Ltv1

* TAP-tagged protein
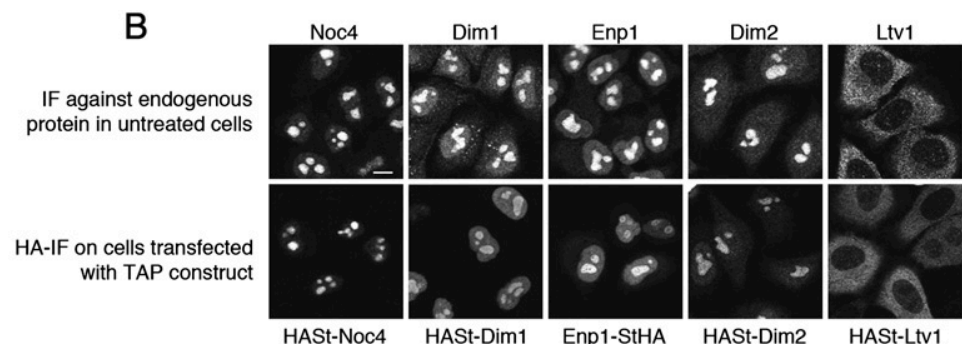

D
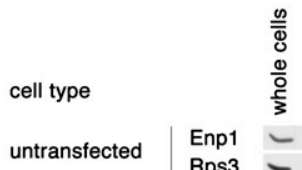

응

Enp1-StHA

HASt-Dim2

HASt-Ltv1

Enp1

$10 \%$ $\underset{\text { sucrose }}{45 \%}$

Enp1-StHA

untransfected

HASt-Ltv1

untransfected

HASt-Dim1

untransfected Rps3

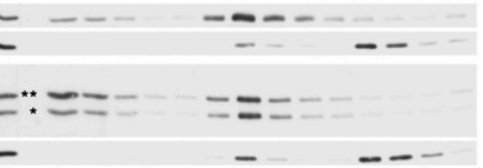

Rps3

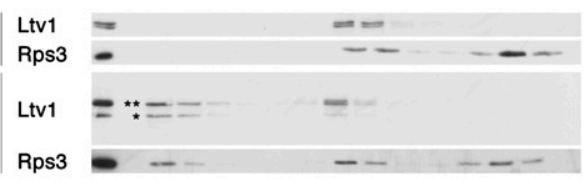

HASt-Dim2

$\operatorname{Dim} 1$
Rps3

Dim1

-

Rps3

Dim2
Rps3

Dim2

Rps3

untransfected

Noc4
Rps3

HASt-Noc4

Noc4
Rps3
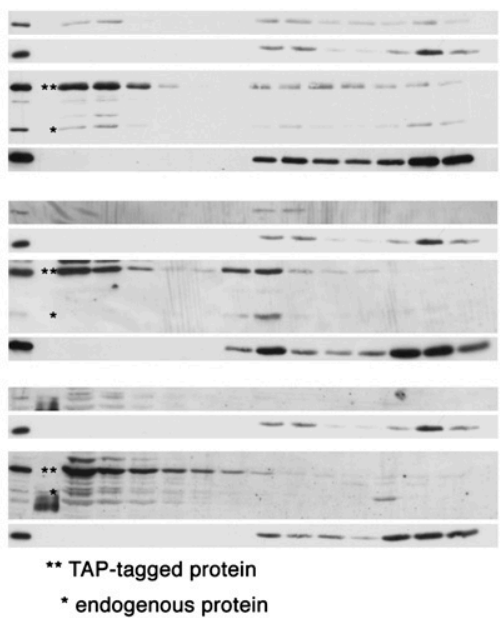

FIGURE 1. Preparation of HASt-TAP cell lines. (A) Schematic overview of the HASt-TAP purification. (B) HASt-TAP-tagged constructs localize like endogenous proteins in HeLaK cells. Either HeLaK cells were transiently transfected with HASt-TAP constructs and the localization of the tagged proteins was analyzed by immunofluorescence using the HA-11 antibody, or nontransfected cells were subjected to immunofluorescence using polyclonal antibodies against the endogenous protein. Scale bar, $10 \mu \mathrm{m}$. (C) Induction with tetracycline leads to expression of HASt-TAPtagged bait proteins. Cells were cultured in the presence or absence of $0.5 \mu \mathrm{g} / \mathrm{mL}$ tetracycline for $24 \mathrm{~h}$, followed by Western blot analysis. No bait: nontransfected cells. (D) Sucrose gradient analyses of HASt-TAP cell lines. Extracts from HEK 293 FlpIn TRex cells in which expression of the indicated bait protein was induced for $24 \mathrm{~h}$ with $0.5 \mu \mathrm{g} / \mathrm{mL}$ tetracycline were fractionated on $10 \%-45 \%$ sucrose gradients. Fractions derived from the gradients were analyzed by Western blotting.

while early nucleolar precursors may not be accessible under these conditions, late nucleolar as well as nucleoplasmic and cytoplasmic particles can be purified. Next, we determined background contaminants of our TAP procedure by performing the purification from cells expressing the tag alone or HASt-GFP as a bait (Fig. 2B). Silver staining analysis revealed that no proteins were purified using the tag alone as bait. Note that the HASt peptide could not be detected in cell lysates (data not shown), suggesting that this short peptide is unstable without a fusion partner. In the HASt-
GFP purification, only the bait protein and two weak degradation products were detected, indicating that the overall background of the purification is very low.

We then went on and performed TAP of the five different HASt-tagged 40S trans-acting factors-Noc4, Dim1, Enp1, Dim2, and Ltv1. Silver staining analysis of the TAP eluates showed that ribosomal particles were successfully co-purified with Dim1, Enp1, Dim2, Ltv1, and to a lower extent with Noc4 (Fig. 2C). In contrast, attempts to tandem-affinitypurify another pre-40S associated factor, Nob1, only isolated 


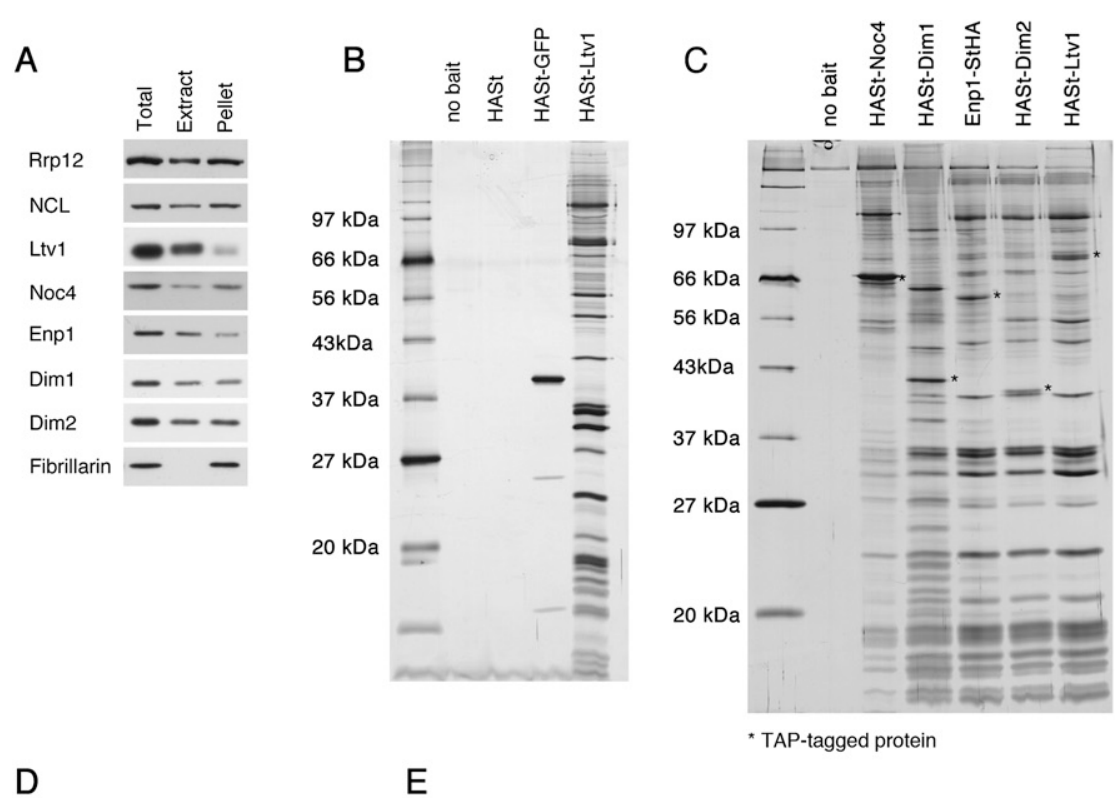

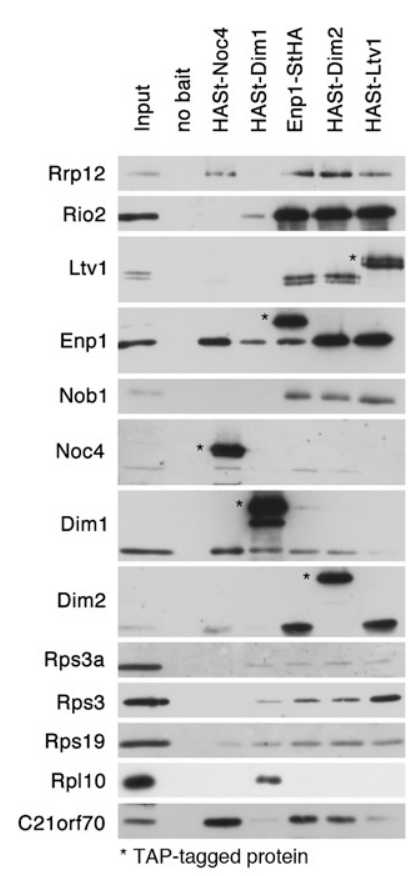

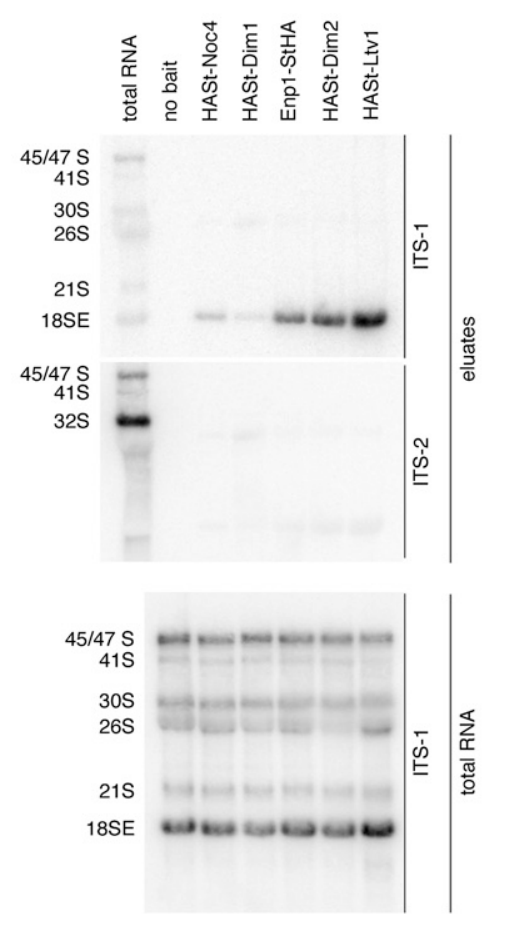

FIGURE 2. Purification of pre-40S particles by HASt-TAP. (A) Extract from nontransfected HEK 293 FlpIn TRex cells was prepared, and equal amounts of total, extract, and pellet fractions were analyzed by Western blotting. $(B)$ Background control. Indicated bait proteins were purified from HEK 293 FlpIn TRex cells after induction for $24 \mathrm{~h}$ with $0.5 \mu \mathrm{g} / \mathrm{mL}$ tetracycline. Eluates were analyzed by SDS-PAGE followed by silver staining. (C) Purification of pre-40S particles. Indicated bait proteins were induced for $24 \mathrm{~h}$ with $0.5 \mu \mathrm{g} / \mathrm{mL}$ tetracycline in HEK 293 FlpIn TRex cells, followed by HASt-TAP purification. Eluates were analyzed as in $B$. (D) Western blot analysis of HASt-TAP purifications. (E) Northern blot analysis of total RNA from HASt-TAP cell lines and HASt-TAP purifications using ITS-1 or ITS-2 probes. Note that samples analyzed by Western blotting in $D$ correspond to samples from panel $C$, whereas samples analyzed by Northern blotting in $E$ correspond to an independent experiment. No bait: nontransfected cells. the bait protein, and no proteins at all were purified with Rio2 as bait, using either $\mathrm{N}$ - or C-terminally tagged Rio2 (data not shown). The position of the HASt-TAP tag can influence whether or not a pre-ribosomal particle can be copurified with the bait protein. For Noc4 and to a lesser extent for Dim1 and Dim2, particle purification was more efficient with an $\mathrm{N}$-terminal tag, whereas for Enp1 only a C-terminal StHA-TAP tag worked (data not shown).

Western blot analysis of the particles isolated using HASt-TAP-Noc4, HAStTAP-Dim1, Enp1-StHA-TAP, HAStTAP-Dim2, and HASt-TAP-Ltv1 revealed that they contain ribosomal proteins of the small subunit, as well as several transacting factors, indicating that they represent pre-ribosomal particles (Fig. 2D). Analysis of the RNA content of the isolated complexes showed that most of the purifications contained 18S-E pre-rRNA, the last precursor to mature $18 \mathrm{~S}$ rRNA, confirming that the corresponding particles represent $40 \mathrm{~S}$ subunit precursors (Fig. 2E).

For Enp1-StHA-TAP, HASt-TAPDim2 and HASt-TAP-Ltv1, several precursors with similar compositions were purified (Fig. 2C,D). The main components of these human $40 \mathrm{~S}$ subunit precursors are Tsr1, Nucleolin, Rio2, Ltv1, Enp1, Nob1, and Dim2, as well as ribosomal proteins of the small subunit and $18 \mathrm{~S}-\mathrm{E}$ pre-rRNA. Overall, these $40 \mathrm{~S}$ precursors closely resemble the pre-40S particles described in yeast (Schafer et al. 2003), suggesting high conservation of the ribosome biogenesis pathway between yeast and human cells. Purification of HASt-TAP-Dim1 led to a more complex pattern of co-purifying factors, as both small and large subunit ribosomal proteins were detected (Fig. 2C,D). This result is consistent with sucrose gradient analysis for Dim1, which revealed that the protein is associated not only with $40 \mathrm{~S}$ but also larger ribosomal particles (Fig. 1D). Moreover, only low levels of 18S-E pre-rRNA were co-purified with HASt-TAP-Dim1, suggesting that HASt-TAP-Dim1 may be associated with mature subunits rather than pre-ribosomes (Fig. 2E; see Discussion). 
Mass spectrometry analysis of the Ltv1- and Noc4associated proteins further confirmed that the particles isolated by TAP correspond to ribosomal precursors (Fig. 3A; Supplemental Table S1), as $40 \mathrm{~S}$ ribosomal proteins were detected and many of the identified nonribosomal proteins have been implicated in ribosome biogenesis (Ginisty et al. 1998; Jakel and Gorlich 1998; Turner et al. 2009; Zemp et al. 2009). Analysis of the eluted proteins by silver staining showed that not all co-purifying proteins are present in stoichiometric amounts compared to the bait proteins, indicating that either different populations of particles were purified or that some factors were partially lost during purification. The analysis of HASt-TAP-Noc4 revealed one protein band that was detected in nearly stoichiometric amounts compared to the bait protein. Most tryptic peptides derived from this band corresponded to NOP14 (Supplemental Table S1), indicating the presence of a small protein complex consisting of HASt-TAP-Noc4 and NOP14 in this purification. This finding is in agreement with the migration of the majority of HASt-TAP-Noc4 in the top fractions of sucrose gradients (Fig. 1D), and a Noc4p-Nol14p complex has recently been reported to exist in yeast (Kuhn et al. 2009). In addition, low amounts of a pre-ribosomal particle were associated with HASt-TAP-Noc4,

A

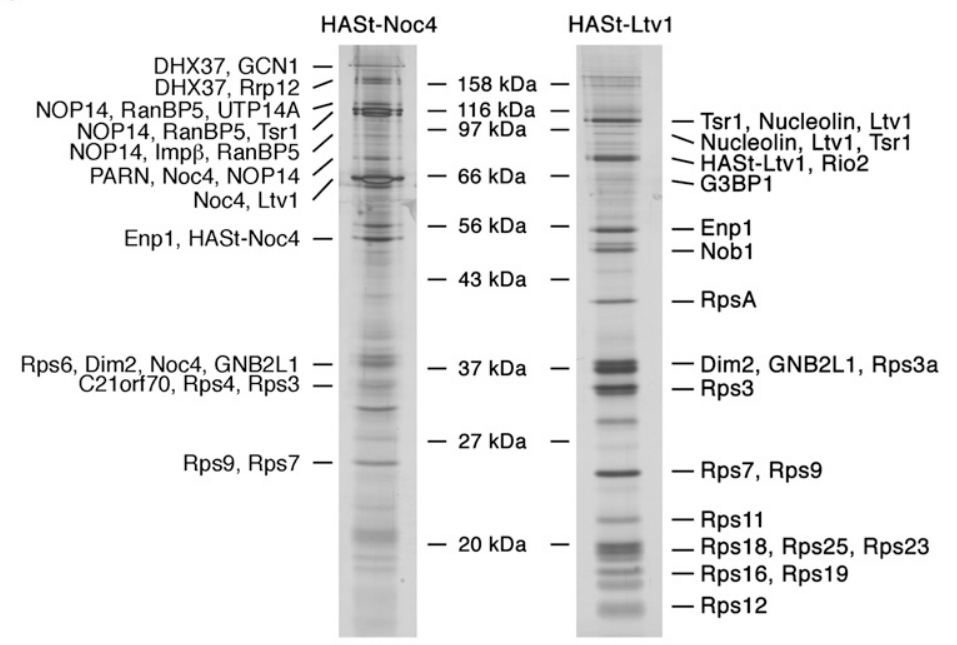

B
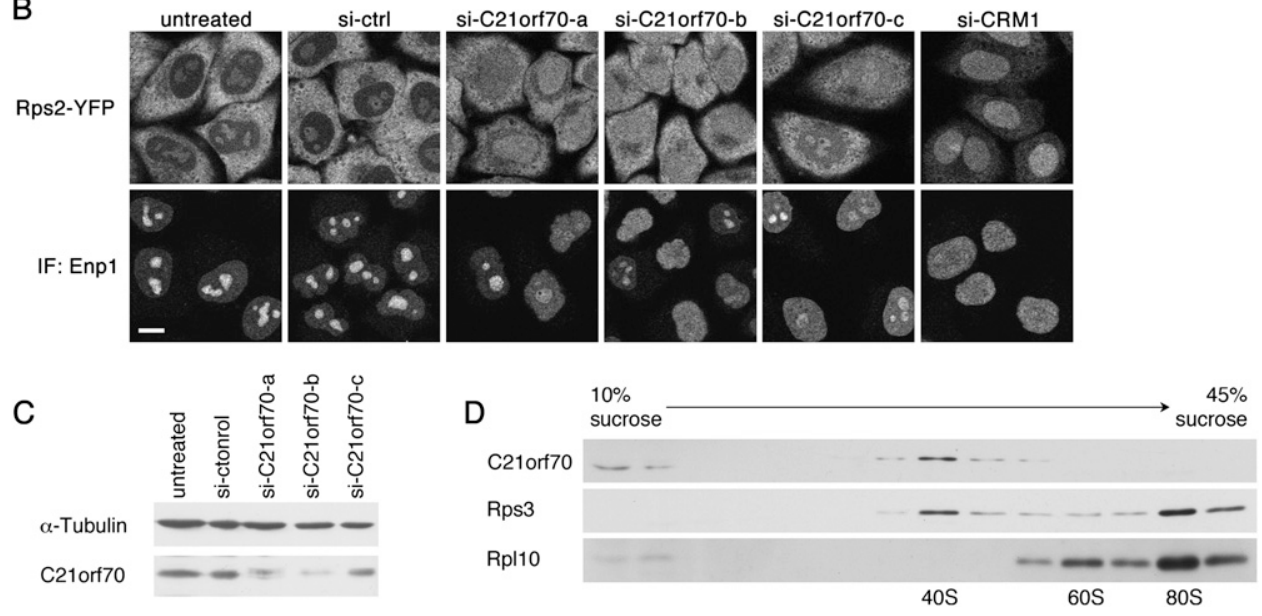

FIGURE 3. Mass spectrometry analysis of purified HASt-TAP particles leads to the identification of C21orf70 as a novel pre-40S trans-acting factor. (A) Bands from the HASt-TAP-Noc4 and HASt-TAP-Ltv1 purifications were cut from the gel and subjected to MS analysis. Note that GNB2L1/RACK1 has been described as a 40S component (Sengupta et al. 2004; Chandramouli et al. 2008). (B) Depletion of C21orf70 leads to nuclear 40S maturation defects. Rps2-YFP reporter cell lines (upper row) or HeLaK cells (lower row) were depleted of C21orf70 by transient transfection of three different siRNAs targeting C21orf70. A control oligonucleotide was used as negative control, depletion of the 40S export receptor CRM1 as positive control. After $72 \mathrm{~h}$ of RNAi, Rps2-YFP reporter cells were fixed and analyzed for YFP fluorescence, and HeLaK cells were analyzed for Enp1 localization using immunofluorescence staining. Scale bar, $10 \mu \mathrm{m}$. $(C)$ Western blot analysis of $B$. Note that only samples from Rps2-YFP cells are shown. C21orf70 down-regulation efficiencies in HeLaK cells were similar (data not shown). (D) C21orf70 co-sediments with $40 \mathrm{~S}$ subunits on sucrose gradients. Extracts from HeLaK cells were fractionated on $10 \%-45 \%$ sucrose gradients, and the fractions were analyzed by Western blotting. 
indicated by the pattern of ribosomal proteins observed by silver staining (Fig. 2C) and the presence of Rps19, Dim2, Enp1, and Rrp12 as detected by immunoblotting and MS analysis (Figs. 2E, 3A). Further factors identified by mass spectrometry included DHX37, a DEAD/DEAH-box helicase protein with homology with $\mathrm{Dhrlp} / \mathrm{Ecm} 16 \mathrm{p}$, a protein associated with U3 snoRNA and involved in early processing events (Colley et al. 2000). Moreover, NOP14 and UTP14A were detected in HASt-TAP-Noc4-associated complexes. The corresponding homologs in yeast, Nop14p and Utp14p, are both components of the SSU processome (Dragon et al. 2002; Grandi et al. 2002). Thus, several proteins associated with HASt-TAP-Noc4 possess orthologs in yeast that join $90 \mathrm{~S}$ pre-ribosomes as part of the SSU processome.

Among the proteins identified by MS analysis of the HASt-TAP-Noc4 purification was C21orf70, a previously uncharacterized protein (Fig. 3A). To test whether C21orf70 may be a novel factor involved in $40 \mathrm{~S}$ maturation, we determined the effects of C21orf70 depletion by RNAi on $40 \mathrm{~S}$ maturation using a previously described reporter cell line, in which $40 \mathrm{~S}$ biogenesis can be followed using an inducible Rps2-YFP reporter (Zemp et al. 2009). Knockdown of C21orf70 led to a partial nuclear accumulation of Rps2YFP in the nucleus, suggesting a nuclear maturation or export defect of $40 \mathrm{~S}$ precursors in absence of C21orf70 (Fig. $3 \mathrm{~B}$, upper panel). Moreover, depletion of C21orf70 from HeLaK cells resulted in increased nucleoplasmic staining for the trans-acting factor Enp1, supporting a role for C21orf70 in nuclear maturation (Fig. 3B, lower panel). Finally, sucrose gradient analysis revealed that C21orf70 partially co-sedimented with $40 \mathrm{~S}$ precursors (Fig. 3D). In summary, purification of HASt-TAP-Noc4 allowed us to identify C21orf70 as a novel component of human 40S precursors that is required for $40 \mathrm{~S}$ maturation.

\section{In absence of Rio2, increased levels of Rrp12 are associated with $40 \mathrm{~S}$ pre-ribosomes}

To investigate the function of a particular trans-acting factor in ribosome biogenesis, it is important to understand how the absence of the factor of interest affects the composition and levels of ribosomal precursors. In an attempt to establish a procedure to address such questions, we combined our TAP cell lines with a system that allows for the inducible knockdown of gene expression (van de Wetering et al. 2003). As a proof of principle, HASt-TAP-Ltv1 cells were stably transfected with pTER-shRio2, which enables tetracyclineinducible knockdown of Rio2 expression. After selection, several clones were tested for tetracycline-dependent knockdown of Rio2 (data not shown), and the clone displaying the strongest Rio2 depletion was chosen for further experiments.

To determine whether absence of Rio2 leads to changes in pre-40S particle composition, HASt-TAP-Ltv1 purification was performed from control as well as shRio2-induced cells. Silver staining analysis of the purifications revealed only few changes between the two conditions (Fig. 4A), indicating that the presence of Rio2 is not essential for assembly of $40 \mathrm{~S}$ precursors. Western blot analysis revealed that, as expected, Rio2 levels in the purified particle were reduced (Fig. 4A). The levels of most trans-acting factors co-purifying with HASt-TAP-Ltv1 were not affected by shRio2 induction, indicating that wild-type levels of Rio2 are not a prerequisite for pre-40S association of these proteins. Intriguingly, Rrp12, the human homolog of a transacting factor required for pre-40S and pre-60S maturation in yeast (Schafer et al. 2003; Oeffinger et al. 2004), was extracted more efficiently from HEK 293 cells after Rio2 knockdown, and higher levels of Rrp12 were detected to

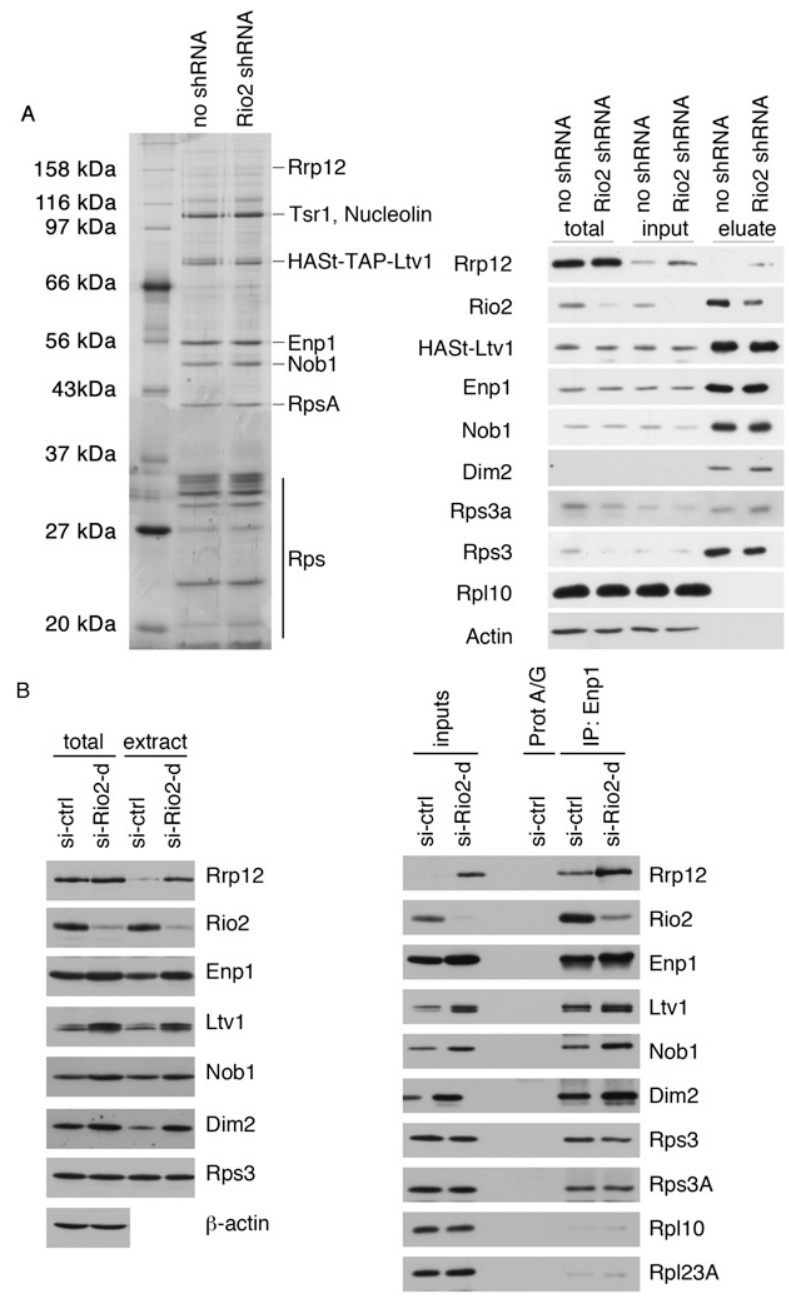

FIGURE 4. Rrp12 is enriched on pre-40S particles after Rio2 depletion. (A) HASt-TAP-Ltvl was purified from cells containing no shRNA or cells in which shRio 2 was induced for $72 \mathrm{~h}$. The purification was analyzed by silver staining (left panel) and Western blotting (right panel). (B) Extracts were prepared from HeLaK control cells and cells depleted of Rio2 by transient transfection of siRio2-d, followed by Western blot analysis (left panel). Extracts were used for Enp1 immunoprecipitation, which was analyzed by Western blotting (right panel). Rio2 depletion efficiency was $\sim 80 \%$ in HASt-TAP-Ltv1 cells and $\sim 85 \%$ in HeLaK cells. 
co-purify with HASt-TAP-Ltv1 (Fig. 4A). These data suggest that Rrp12 association with $40 \mathrm{~S}$ precursors is enhanced in the absence of Rio2, which could imply a role for Rio2 in release of Rrp12 from 40S precursors.

To validate the method and confirm that Rio2 depletion leads to increased association of Rrp12 with 40S precursors, we used another approach to isolate $40 \mathrm{~S}$ precursors, namely, Enp1 immunoprecipitation. HeLaK cells were depleted of Rio2 by transient siRNA transfection, followed by immunoprecipitation of Enp1. Enp1 co-precipitates several 40S trans-acting factors like Rio2, Ltv1, Nob1, and Dim2, as well as $40 \mathrm{~S}$ ribosomal proteins like Rps3 and Rps3A (Fig. $4 \mathrm{~B})$. These data show that Enp1 immunoprecipitation allows for purifying $40 \mathrm{~S}$ precursors. In Rio2-depleted cells, Rrp12 is more efficiently extracted compared to control cells (Fig. 4B), as observed in HEK 293 cells. Moreover, higher amounts of Rrp12 were co-precipitated with Enp1 after Rio2 RNAi, which suggests that the extracted pool of Rrp12 may be associated with $40 \mathrm{~S}$ precursors in the absence of Rio2 and confirms the results from the HASt-TAP-Ltv1/ shRio2 experiment. Interestingly, levels of Dim2, Nob1, and Ltv1 co-precipitated with Enp1 were also increased upon Rio2 depletion. Notably, Dim2, Nob1, and Ltv1 all depend on Rio2 to be released from $40 \mathrm{~S}$ precursors after nuclear export (Zemp et al. 2009), indicating that the same might also apply to Rrp12.

\section{Rio2 kinase activity is required for recycling of Rrp12 from cytoplasmic $40 S$ subunit precursors}

Since the bait protein HASt-TAP-Ltv1 does not exclusively co-sediment with pre-40S particles as analyzed by sucrose gradient analysis (Fig. 1D), the increased levels of Rrp12 copurified with HASt-TAP-Ltvl could be due to binding of Rrp12 to free HASt-TAP-Ltv1 or to increased pre-40S association of Rrp12. Similarly, the Enp1 immunoprecipitation experiment from extract of HeLaK cells does not distinguish between free Enp1 and 40S-associated Enp1, thus it does not conclusively reveal in what form Rrp12 is present in these purifications. In order to address this question, we performed sucrose gradient analysis of extracts from control or Rio2-depleted HEK 293 and HeLaK cells (Fig. 5). In both cell lines, Rrp12 co-sediments with $40 \mathrm{~S}$ precursors in the absence of Rio2, indicating that the increased levels of Rrp12 in the Ltv1-TAP purification and in the Enp1 immunoprecipitation are due to increased association of Rrp12 with late 40S particles, suggesting a failure in release of Rrp12 from 40S precursors in the absence of Rio2.

Rio2 is required for recycling of several trans-acting factors from late $40 \mathrm{~S}$ precursors in the cytoplasm (Zemp et al. 2009). To test whether Rio2 depletion similarly affects Rrp12 recycling from cytoplasmic pre-40S particles, we investigated the localization of Rrp12 after Rio2 RNAi experiments. This analysis was performed in HeLaK cells since the morphology of HEK 293 cells hampers micro-
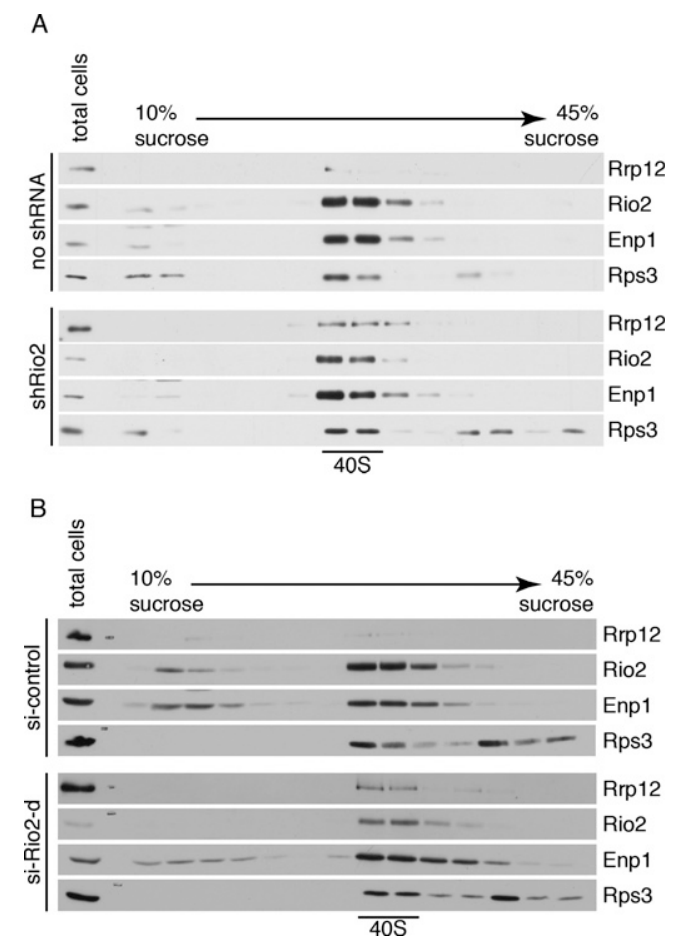

FIGURE 5. Rrp12 is associated with pre-40S particles after Rio2 depletion. Extracts from untreated or shRio2-induced HEK 293 cells $(A)$ or control or Rio2-depleted HeLaK cells $(B)$ prepared for Figure 3 were fractionated on $10 \%-45 \%$ sucrose gradients. Fractions derived from the gradients were analyzed by Western blotting. Note that Rrp12 is poorly extracted from control cells (Fig. 4) and hence present in low amounts in the control extracts analyzed on these gradients.

scopic analyses. In HeLaK cells, Rrp12 predominantly localizes to nucleoli in control cells (Fig. 6A). While RNAi against Rio2 did not affect the localization of Noc4, both Enp1 and Dim2 were partially mislocalized to the cytoplasm (Fig. 6A), reflecting recycling defects of these proteins as previously described (Zemp et al. 2009). For Rrp12, depletion of Rio2 led to a partial mislocalization to the cytoplasm similar to Enp1 and Dim2. The effect on Rrp12 is not as pronounced as the effects on Enp1 or Dim2, as the nucleolar signal for Rrp12 is still very strong in the absence of Rio2. However, as yeast Rrp12p has been described to be a component of both $40 \mathrm{~S}$ and $60 \mathrm{~S}$ precursors (Oeffinger et al. 2004), this result may be due to a subpopulation of Rrp12 associated with pre-60S particles, the localization of which would not be affected by depletion of Rio2. Based on these observations, we conclude that Rio2 is required for recycling of Rrp12 from cytoplasmic 40S precursors, allowing for its re-import into the nucleus.

To test whether Rio2 kinase activity is required for its role in Rrp12 recycling, rescue experiments were performed using EGFP-tagged wild-type (WT) and kinase-dead (KD) Rio2 (Fig. 6B-D). As expected, the mislocalization of Rrp12 to the cytoplasm after RNAi against Rio2 could be rescued by overexpression of wild-type EGFP-Rio2. In contrast, EGFP-hRio2(KD) was not able to restore the predominantly 

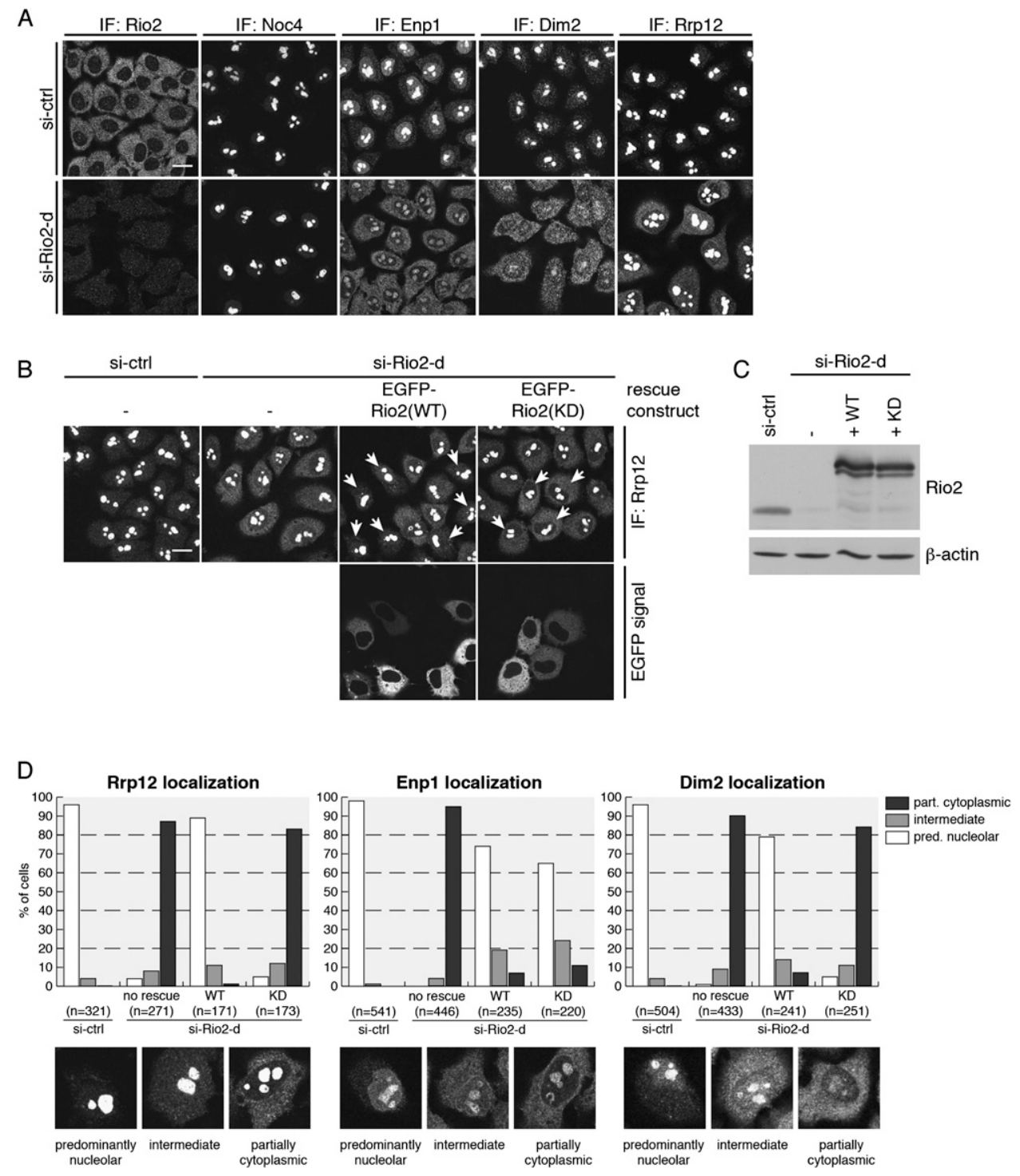

FIGURE 6. Rio 2 kinase activity is required for cytoplasmic recycling of Rrp12 from pre-40S particles. (A) Rrp 12 is partially mislocalized to the cytoplasm after Rio2 knockdown. HeLaK cells were transfected with si-ctrl or si-Rio2-d. After $48 \mathrm{~h}$ cells were fixed, followed by immunofluorescence (IF) analysis for the trans-acting factors indicated. (B) Wild-type (WT) but not kinase-dead (KD) EGFP-Rio2 rescues Rrp12 mislocalization to the cytoplasm after Rio2 depletion. RNAi experiments were performed as in $(A)$. In addition, cells were transfected with EGFP-tagged rescue constructs after $24 \mathrm{~h}$ of RNAi. Note that rescue phenotypes are only observed in cells transfected with the EGFP-tagged rescue constructs (marked with arrows). $(C)$ Western blot analysis of $B$. (D) Quantification of the rescue experiment. Cells displaying predominantly nucleolar, intermediate, or partially cytoplasmic localization of Rrp12, Enp1, and Dim2 were counted manually; examples for the classification are depicted below the graphs. For rescues, only transfected cells were counted. n: Number of cells counted (from one representative experiment). Scale bars, $10 \mu \mathrm{m}$. Note that for Rrp12 immunofluorescence analyses, images were processed in parallel by enhancing levels, followed by setting gamma correction to 0.8 .

nucleolar Rrp12 localization observed in control cells, indicating that Rio2 kinase activity is necessary for normal Rrp12 localization. Together, our results indicate that the kinase activity of Rio2 is required for the release of Rrp 12 from cytoplasmic $40 \mathrm{~S}$ precursors.

\section{DISCUSSION}

In our study, we have applied tandem affinity purification to isolate $40 \mathrm{~S}$ subunit precursors from human cells and were able to characterize several late $40 \mathrm{~S}$ precursors associated with the bait proteins Dim2, Enp1, and Ltv1. The use of tandem affinity tags for the purification of human pre-ribosomes has several advantages. First, due to the two affinity purification steps, this method is much cleaner than previously employed methods using immunoprecipitation. Second, the method does not rely on time-consuming generation of antibodies that are functional in immunoprecipitation of particle-associated trans-acting factors. Third, our method allows for a relatively fast purification of these 
precursors under mild conditions. Using this approach, we were able to identify the core components of human $40 \mathrm{~S}$ subunit precursors. Among the identified proteins were not only small subunit ribosomal proteins, but also trans-acting factors such as Tsr1, Nucleolin, Rio2, Ltv1, Enp1, Nob1, and Dim2. All these proteins possess homologs in yeast that are known pre-40S components. Nucleolin has been previously described to be required for early ribosome biogenesis steps such as rRNA transcription, assembly of early ribosomal precursors, and early pre-rRNA processing steps (Ginisty et al. 1998; Roger et al. 2003; Rickards et al. 2007). It may be that a potential function of Nucleolin in later stages of $40 \mathrm{~S}$ maturation was not previously detected because of the defects occurring in its absence in earlier maturation steps. Alternatively, the association of Nucleolin with HASt-Ltv1 may not reflect a Nucleolin function in late $40 \mathrm{~S}$ maturation but rather indicate that Nucleolin is released from pre-40S particles at a nucleoplasmic or even cytoplasmic stage and that this release is not yet completed in Ltv1-associated particles.

In addition to homologs of yeast pre-40S components, we identified C21orf70, for which there is no known yeast homolog, as a novel component of human $40 \mathrm{~S}$ precursors and could show that its depletion leads to pre-40S maturation defects. For several other proteins like PARN, further experimental work is required to determine whether they are components of $40 \mathrm{~S}$ precursors specific to human cells or whether they represent contaminants of the particles.

Analysis of the different TAP purifications shows that Enp1-StHA-TAP, HASt-TAP-Dim2, and HASt-TAP-Ltv1 are associated with particles of very similar composition. Moreover, most trans-acting factors associated with these particles were also found in a previous pre-40S purification using Rio2 immunoprecipitation (Zemp et al. 2009), indicating that these complexes represent late $40 \mathrm{~S}$ precursors. In contrast, the purifications using HASt-TAP-Noc4 and HASt-TAP-Dim1 yielded very different results. HASt-TAPNoc4 predominantly purified a small subcomplex consisting of Noc4 and NOP14, which has recently been described to also exist in yeast (Kuhn et al. 2009). This result is consistent with the sedimentation behavior of HASt-TAP-Noc4, which was mostly detected at the top of the gradient with the extraction conditions used (Fig. 1D). HASt-TAP-Dim1 was associated with both small and large subunit proteins, in agreement with the sucrose gradient analysis for the bait protein, which was detected both in 40S- and 80S-containing fractions. Notably, endogenous Dim1 in nontransfected cells displays a similar sedimentation behavior as HASt-TAPDiml and is also found both in $40 \mathrm{~S}$ and $80 \mathrm{~S}$ fractions. Based on its predominantly nucleolar localization, Dim1 may be associated with early pre-ribosomes, prior to the formation of pre-40S and pre-60S particles, as described previously for its yeast homolog Dimlp (Schafer et al. 2003). However, little 18S-E or earlier pre-rRNA was co-purified with HAStTAP-Diml, suggesting that only low levels of early pre- ribosomes are associated with HASt-TAP-Dim1 (Fig. 2E). In addition, Diml may to some extent also associate with mature ribosomal subunits, as indicated by the low amounts of pre-rRNA in the complex and the presence of Rpl10 in this TAP. Whether this reflects a true association and a function for Dim1 at mature ribosomes or whether this is due to post-lysis association remains unclear at the moment.

One of the core components of $40 \mathrm{~S}$ subunit precursors is the protein kinase Rio2 that is required for the last step of $18 \mathrm{~S}$ rRNA processing in the cytoplasm (Rouquette et al. 2005). Recently, we have described that this function is linked to the role of Rio2 in releasing several trans-acting factors from $40 \mathrm{~S}$ precursors in the cytoplasm. Here, we have used shRNA-mediated depletion of Rio2 in combination with TAP of late pre- $40 \mathrm{~S}$ precursors to investigate how the absence of this factor affects the composition of ribosomal precursors. Notably, depletion of Rio2 did not lead to drastic alterations of the pre-40S particle associated with Ltv1 (Fig. 5), and similar results were obtained using Dim2 or Enp1 as bait proteins (data not shown). Thus, although Rio2 is associated with all analyzed late pre-40S particles, the assembly of $40 \mathrm{~S}$ precursors is not perturbed upon depletion of Rio2.

One notable exception was the increased association of Rrp12 with pre-40S particles isolated on HASt-TAP-Ltv1 or by immunoprecipitation of Enp1, suggesting that the presence of Rio2 is required for the release of Rrp12 from pre$40 \mathrm{~S}$ precursors. Several lines of evidence support this conclusion. First, sucrose gradient analysis revealed that Rrp12 is trapped on $40 S$ precursors in the absence of Rio2. Second, Rrp12 was partially mislocalized from the nucleolus to the cytoplasm in Rio2-depleted HeLaK cells. Third, Rrp12 was more efficiently extracted from Rio2-depleted HEK 293 and HeLaK cells compared to control cells. Together, these results show that Rrp12 is co-exported with $40 \mathrm{~S}$ precursors to the cytoplasm, where Rio2 is required for release of Rrp12 from exported precursors, allowing Rrp12 to be reimported into the nucleus. The co-export of Rrp12 with pre-40S particles to the cytoplasm is in agreement with the proposed function of Rrp12 in pre-40S export in yeast (Oeffinger et al. 2004).

In a previous study, we described that Rio2 is involved in recycling of several 40S trans-acting factors, namely, Enp1, Dim2, Ltv1, and Nob1 (Zemp et al. 2009). The data presented here show that Rio2 is also necessary for Rrp12 recycling. Rescue experiments using wild-type and kinasedead forms of Rio2 place Rrp12 in a group of factors including Dim2, Nob1, and Ltv1, which all require Rio2 kinase activity for their release from $40 \mathrm{~S}$ precursors. It is noteworthy that most trans-acting factors that accompany $40 \mathrm{~S}$ precursors from the nucleus to the cytoplasm are recycled in a Rio2 kinase activity-dependent manner, possibly in a concerted fashion. Rrp12 is a large, $144-\mathrm{kDa}$ protein that contains several HEAT repeats, which are known to function as protein-protein interaction surfaces. Thus, 
Rrp12 might occupy a large surface on the subunit precursor. Release of Rrp12 could be a prerequisite for further maturation of pre-40S in the cytoplasm, for instance, by causing a structural change in the subunit. Alternatively, Rrp12 may also function as a platform for binding of other trans-acting factors to pre-40S particles. How recycling of Rrp12 is triggered at a molecular level is not clear to date, but it is tempting to speculate that Rio2 might phosphorylate Rrp12, thereby triggering Rrp12 recycling and, in turn, enabling the release of other factors from $40 \mathrm{~S}$ precursors that require Rrp12 for pre-40S association. However, so far we have not been able to obtain positive evidence supporting this mechanism. Likely, it will be necessary to identify the substrate(s) of Rio2 to determine the molecular basis for these cytoplasmic Rio2-dependent 40S maturation events.

In summary, we have applied a tandem affinity purification system to isolate and characterize human pre-ribosomes. By combining this procedure with inducible expression of shRNAs to deplete cells of a particular factor, we determined that Rio2 depletion traps Rrp12 on cytoplasmic $40 \mathrm{~S}$ precursors, preventing its recycling to the nucleus and thereby its participation in a next round of ribosome biogenesis. This example reveals the potential of our TAP/ shRNA method to investigate the role of trans-acting factors in ribosome biogenesis and other biochemical processes.

\section{MATERIALS AND METHODS}

\section{Molecular cloning}

The tetracycline-inducible TAP system in human HEK 293 cells (FlpIn TRex; Invitrogen) was adapted from Glatter et al. (2009). Vectors pcDNA5/FRT/TO/nHASt-TAP and pcDNA5/FRT/TO/ cStHA-TAP were prepared to allow for $\mathrm{N}$ - or $\mathrm{C}$-terminal tagging of the bait protein, respectively. For the N-terminal tag, oligos nHASt-TAP_1, nHASt-TAP_2, nHASt-TAP_3, and nHASt-TAP_4 (Supplemental Table S2) were assembled using Pwo DNA polymerase, and the resulting fragment was inserted into the KpnI/ HindIII sites of pcDNA5/FRT/TO (Invitrogen). Similarly, the C-terminal tag was assembled from cStHA-TAP_1, cStHA-TAP_2, cStHA-TAP_3, and cStHA-TAP_4 (Supplemental Table S2) and inserted into the ApaI/XhoI sites of pcDNA5/FRT/TO. Coding regions for bait proteins were amplified from HeLaK cell cDNA (Dim1, Noc4) or previously described plasmids (Dim2, Enp1, Ltv1) (Zemp et al. 2009) and inserted into pcDNA5/FRT/TO/ nHASt-TAP or pcDNA5/FRT/TO/cStHA-TAP using BamHI/XhoI (Noc4, Dim1, Dim2, Ltv1) or KpnI/NotI (Enp1).

The shRNA vector is based on the pTER vector (van de Wetering et al. 2003). As the original pTER contains a zeocin resistance and the HEK 293 FlpIn TRex cells are at least partially resistant against zeocin after insertion of a gene in the FRT site (Invitrogen information), the shRNA cloning cassette was transferred to pcDNA3.1+/Neo (Invitrogen) using PvuI/HindIII to generate pTER-Neo. pTER-shRio2 was generated by inserting the DNA duplex from the oligos shRio2-d-s and shRio2-d-as (Supplemental Table S2) into the BglII/HindIII sites of pTER-Neo.

\section{Generation of cell lines}

HEK 293 cell lines with inducible TAP-tagged baits were generated as described (Invitrogen) (Glatter et al. 2009). Briefly, $0.1 \mu \mathrm{g}$ of plasmid containing the TAP-tagged bait was co-transfected with $0.9 \mu \mathrm{g}$ of pOG44 plasmid into HEK 293 FlpIn TRex cells (Invitrogen). Cells were selected for $\sim 2 \mathrm{wk}$ in standard medium containing $100 \mu \mathrm{g} / \mathrm{mL}$ hygromycin and $15 \mu \mathrm{g} / \mathrm{mL}$ blasticidin. Afterward, all growing cell foci were pooled, yielding a polyclonal TAP cell line.

For insertion of the Rio2-shRNA cassette into the genome, the TAP cell lines were transfected with pTER-shRio2 and selected for $2-3$ wk in standard medium containing $100 \mu \mathrm{g} / \mathrm{mL}$ hygromycin, $15 \mu \mathrm{g} / \mathrm{mL}$ blasticidin, and $625 \mu \mathrm{g} / \mathrm{mL}$ G418. Individual cell foci were isolated and tested for knockdown efficiency.

\section{Antibodies}

Antibodies against Noc4, Dim1, Rps3A, and Rps19 were raised against purified recombinant His-tagged proteins and affinitypurified using the respective antigens coupled to SulfoLink (Thermo Fisher Scientific). Peptide-specific antibodies against an internal (C-SDLTVDAVKLHNELQSG) and a C-terminal (C-GSQVGHKNRRKDRRP) peptide of Rrp12 were also raised in rabbits and affinity-purified. The antibody targeting the internal peptide was used for immunofluorescence analysis, the antibody against the C-terminal peptide for Western blotting. Anti- $\beta$-Actin antibody was purchased from Sigma-Aldrich, anti-Rpl10, antiC21orf70, and anti-Fibrillarin from Santa Cruz, anti-Nucleolin from Abcam, anti-HA-11 from Covance, and secondary antibodies for immunofluorescence analysis from Invitrogen. AntiRpl23A was raised as previously described in Pool et al. (2002). All other antibodies have been described previously (Zemp et al. 2009).

\section{Preparation of cell extracts}

Cells were seeded such that they reached confluency on the day the TAP was performed. Expression of the bait protein was induced with $0.5 \mu \mathrm{g} / \mathrm{mL}$ tetracycline $24 \mathrm{~h}$ before the TAP procedure. For TAP in combination with shRNA induction, cells were induced 72 $\mathrm{h}$ before harvesting with $1 \mu \mathrm{g} / \mathrm{mL}$ tetracycline and again $40 \mathrm{~h}$ before harvesting with additional $0.5 \mu \mathrm{g} / \mathrm{mL}$ tetracycline.

For TAPs, cells were detached with PBS containing $0.5 \mathrm{mM}$ EDTA and lysed in $10 \mathrm{mM}$ Tris ( $\mathrm{pH} 7.6), 100 \mathrm{mM} \mathrm{KCl}, 2 \mathrm{mM}$ $\mathrm{MgCl}_{2}, 1 \mathrm{mM}$ DTT, $0.5 \% \mathrm{NP}-40$ substitute (Fluka) containing protease and phosphatase inhibitors using a douncer or a $20 \mathrm{G}$ needle for small volumes. Two milliliters of lysis buffer was used per $1.5 \times 10^{7}$ cells. After lysis, the extracts were cleared by centrifugation at $5000 \mathrm{~g}$ for $12 \mathrm{~min}$ at $4^{\circ} \mathrm{C}$.

For TAPs combined with shRNA induction or for RNAi experiments, extract was prepared as previously described (Zemp et al. 2009). Briefly, cells were lysed in $10 \mathrm{mM}$ Tris ( $\mathrm{pH} \mathrm{7.6),} 10$ $\mathrm{mM} \mathrm{KCl}, 2 \mathrm{mM} \mathrm{MgCl}$, 0.05\% Triton X-100, $1 \mathrm{mM}$ DTT, $1 \mathrm{mM}$ EGTA, and protease inhibitors. For TAPs/shRNA experiments, $2 \mathrm{~mL}$ of lysis buffer was used per $1.5 \times 10^{7}$ cells. For RNAi experiments, $400 \mu \mathrm{L}$ of lysis buffer was used per $6 \times 10^{6}$ cells.

\section{Tandem affinity purification}

The TAP method was adapted from Glatter et al. (2009). All steps were performed at $4^{\circ} \mathrm{C}$. Centrifugation of cells and beads was 
performed at $800 \mathrm{~g}$, and washing of beads was performed by resuspension of the beads in $1 \mathrm{~mL}$ of buffer, followed by centrifugation.

Extracts prepared from stable 293 FlpIn TRex cell lines were incubated with pre-equilibrated StrepTactin beads (IBA, $25 \mu \mathrm{L}$ of beads suspension per $1.5 \times 10^{7}$ cells) for $30 \mathrm{~min}$ in an overhead shaker. After the first incubation step, beads were transferred to $1.5 \mathrm{~mL}$ of Eppendorf tubes and washed three times with TAP buffer $\left(10 \mathrm{mM}\right.$ Tris at $\mathrm{pH} 7.6,100 \mathrm{mM} \mathrm{KCl}, 2 \mathrm{mM} \mathrm{MgCl}_{2}, 0.1 \mu \mathrm{g} /$ $\mathrm{mL}$ pepstatin, $10 \mu \mathrm{g} / \mathrm{mL}$ aprotinin, $10 \mu \mathrm{g} / \mathrm{mL}$ leupeptin, $0.1 \mathrm{mM}$ $\mathrm{Na}_{3} \mathrm{VO}_{4}, 0.5 \mathrm{mM} \mathrm{NaF}$ ). Bound material was eluted by three consecutive 1-min washes with $300 \mu \mathrm{L}$ of TAP buffer supplemented with $2.5 \mathrm{mM}$ desthio-biotin (Sigma). The combined eluates were applied to HA-agarose (Sigma; $20 \mu \mathrm{L}$ of beads suspension per $1.5 \times 10^{7}$ cells starting material) equilibrated in TAP buffer and then incubated for $1 \mathrm{~h}$ in $1.5 \mathrm{~mL}$ of Eppendorf tubes in an overhead shaker. After washing twice with TAP buffer and once with 10 $\mathrm{mM}$ Tris ( $\mathrm{pH} 7.6$ ), $2 \mathrm{mM} \mathrm{MgCl}_{2}$, the purified protein complexes were eluted with two volumes of SDS sample buffer without DTT in Mobicol spin columns (MoBiTec). DTT was added to the eluate to $30 \mathrm{mM}$ final concentration.

\section{Northern blotting}

RNA was isolated from whole cells or from the first eluate of tandem affinity purifications using the RNeasy Mini kit (QIAGEN). For Northern blots from whole cells, $1 \mu \mathrm{g}$ of RNA was loaded per lane, and equal loading of the samples was analyzed by ethidium bromide staining. For Northern blots of RNA purified from TAP eluates, one-third of the isolated RNA was loaded on the gel.

The purified RNA was separated on a $1 \%$ agarose gel in $30 \mathrm{mM}$ triethanolamine, $30 \mathrm{mM}$ tricine, and $1.25 \%$ formaldehyde, transferred to a Hybond- $\mathrm{N}^{+}$membrane (GE Healthcare) in $0.5 \times \mathrm{TBE}$ buffer ( $45 \mathrm{mM}$ Tris base, $44 \mathrm{mM}$ boric acid, and $1 \mathrm{mM}$ EDTA) by electrotransfer, and UV-cross-linked to the membrane. The membrane was prehybridized in $0.5 \mathrm{M}$ sodium phosphate $(\mathrm{pH}$ 7.2), $1 \mathrm{mM}$ EDTA, 7\% SDS, and 1\% BSA for $30 \mathrm{~min}$ and hybridized with a radiolabeled $5^{\prime}$ ITS 1 probe $\left(5^{\prime}\right.$-CCTCGCCCTC CGGGCTCCGTTAATGATC-3') or a radiolabeled ITS2 probe (5'-GCGCGACGGCGGACGACACCGCGGCGTC-3') in the same buffer overnight at $45^{\circ} \mathrm{C}$. After rinsing twice with $2 \times \mathrm{SSC} / 0.1 \%$ SDS and washing once for $10 \mathrm{~min}$ with $1 \times \mathrm{SSC} / 0.1 \%$ SDS, the membrane was exposed for PhosphorImaging.

\section{MS analysis}

Purifications were scaled up about fivefold to yield sufficient material to allow the detection of protein bands on Coomassiestained gels. Bands were then cut from the gel, digested with trypsin, and analyzed by mass spectrometry using nano-LC-ESI on an LTQ-Orbitrap XL (Thermo Fisher).

\section{Transient siRNA transfection, rescue experiments, and immunofluorescence analysis}

For transient transfection of siRNAs, INTERFERin siRNA transfection reagent (Polyplus Transfection) was used according to the manufacturer's instructions. si-Rio2-d (5'-GGAUCUUGGAUAU GUUUAA, targeting the $3^{\prime}$-UTR of Rio2 mRNA), si-C21orf70-a (5'-GGGCGUUCAUCAACACCAA), si-C21 orf70-b (5'-CAAUA
AAUGGCUCUGUGAA), si-C21orf70-c (5'-GCAGCAGGGAGAG CAACAA), and si-ctrl (AllStars; QIAGEN) were used at $5 \mathrm{nM}$ concentration. After $48 \mathrm{~h}$ (Rio2 depletion) or $72 \mathrm{~h}$ (C21orf70 depletion) of RNAi, cells were harvested for extract preparation or Western blotting, or fixed in 4\% PFA for immunofluorescence analysis. For RNAis in Rps2-YFP reporter cells, Rps2-YFP expression was induced with $0.125 \mu \mathrm{g} / \mathrm{mL}$ tetracycline for $15 \mathrm{~h}$, followed by $4 \mathrm{~h}$ incubation in tetracycline-free medium. In rescue experiments, cells were transfected with rescue constructs $24 \mathrm{~h}$ prior to harvest/fixation, using FuGENE transfection reagent (Roche). Immunofluorescence analysis was performed as previously described (Zemp et al. 2009).

\section{Immunoprecipitation}

Enp1-specific antibodies (Zemp et al. 2009), coupled to a 9:1 mixture of protein A:protein G Sepharose beads (GE Healthcare), were incubated with extracts prepared from control- or Rio2depleted cells in $50 \mathrm{mM}$ Tris/ $\mathrm{HCl}$ ( $\mathrm{pH} 7.6), 150 \mathrm{mM} \mathrm{KCH}_{3} \mathrm{CO}_{2}$, $2 \mathrm{mM} \mathrm{MgCl}_{2}$, and $0.001 \%(\mathrm{v} / \mathrm{v})$ Triton X-100. After washing, beads were eluted with SDS-PAGE sample buffer without DTT. DTT was added after the elution, followed by SDS-PAGE and Western blot analysis.

\section{Sucrose gradient analysis}

To analyze association of bait proteins and trans-acting factors with pre-ribosomal particles, sucrose gradient analyses on linear $10 \%-45 \%$ sucrose gradients were performed as previously described (Zemp et al. 2009).

\section{SUPPLEMENTAL MATERIAL}

Supplemental material can be found at http://www.rnajournal.org.

\section{ACKNOWLEDGMENTS}

We thank C. Ashiono for excellent technical assistance as well as R. Ungricht and F. Wandrey for critical comments on the manuscript. Imaging was performed on instruments of the ETH LMC facility. This work was supported by the Swiss National Science Foundation and an intramural ETH grant (both to U.K.).

Received June 18, 2010; accepted October 21, 2010.

\section{REFERENCES}

Bassler J, Grandi P, Gadal O, Lessmann T, Petfalski E, Tollervey D, Lechner J, Hurt E. 2001. Identification of a 60 S preribosomal particle that is closely linked to nuclear export. Mol Cell 8: 517529.

Chandramouli P, Topf M, Menetret JF, Eswar N, Cannone JJ, Gutell RR, Sali A, Akey CW. 2008. Structure of the mammalian 80 S ribosome at 8.7 A resolution. Structure 16: 535-548.

Colley A, Beggs JD, Tollervey D, Lafontaine DL. 2000. Dhrlp, a putative DEAH-box RNA helicase, is associated with the box C+D snoRNP U3. Mol Cell Biol 20: 7238-7246.

Dragon F, Gallagher JE, Compagnone-Post PA, Mitchell BM, Porwancher KA, Wehner KA, Wormsley S, Settlage RE, Shabanowitz J, Osheim Y, et al. 2002. A large nucleolar U3 ribonucleoprotein required for $18 \mathrm{~S}$ ribosomal RNA biogenesis. Nature 417: 967-970. 
Fatica A, Cronshaw AD, Dlakic M, Tollervey D. 2002. Ssf1p prevents premature processing of an early pre-60S ribosomal particle. Mol Cell 9: 341-351.

Forler D, Kocher T, Rode M, Gentzel M, Izaurralde E, Wilm M. 2003. An efficient protein complex purification method for functional proteomics in higher eukaryotes. Nat Biotechnol 21: 89-92.

Fromont-Racine M, Senger B, Saveanu C, Fasiolo F. 2003. Ribosome assembly in eukaryotes. Gene 313: 17-42.

Fujiyama S, Yanagida M, Hayano T, Miura Y, Isobe T, Fujimori F, Uchida T, Takahashi N. 2002. Isolation and proteomic characterization of human Parvulin-associating preribosomal ribonucleoprotein complexes. J Biol Chem 277: 23773-23780.

Gavin AC, Bosche M, Krause R, Grandi P, Marzioch M, Bauer A, Schultz J, Rick JM, Michon AM, Cruciat CM, et al. 2002. Functional organization of the yeast proteome by systematic analysis of protein complexes. Nature 415: 141-147.

Ginisty H, Amalric F, Bouvet P. 1998. Nucleolin functions in the first step of ribosomal RNA processing. EMBO J 17: 1476-1486.

Glatter T, Wepf A, Aebersold R, Gstaiger M. 2009. An integrated workflow for charting the human interaction proteome: insights into the PP2A system. Mol Syst Biol 5: 237. doi: 10.1038/msb.2008.75.

Grandi P, Rybin V, Bassler J, Petfalski E, Strauss D, Marzioch M, Schafer T, Kuster B, Tschochner H, Tollervey D, et al. 2002. 90 S pre-ribosomes include the $35 \mathrm{~S}$ pre-rRNA, the U3 snoRNP, and $40 \mathrm{~S}$ subunit processing factors but predominantly lack $60 \mathrm{~S}$ synthesis factors. Mol Cell 10: 105-115.

Harnpicharnchai P, Jakovljevic J, Horsey E, Miles T, Roman J, Rout M, Meagher D, Imai B, Guo Y, Brame CJ, et al. 2001. Composition and functional characterization of yeast 66S ribosome assembly intermediates. Mol Cell 8: 505-515.

Hayano T, Yanagida M, Yamauchi Y, Shinkawa T, Isobe T, Takahashi N. 2003. Proteomic analysis of human Nop56p-associated preribosomal ribonucleoprotein complexes. Possible link between Nop56p and the nucleolar protein treacle responsible for Treacher Collins syndrome. J Biol Chem 278: 34309-34319.

Henras AK, Soudet J, Gerus M, Lebaron S, Caizergues-Ferrer M, Mougin A, Henry Y. 2008. The post-transcriptional steps of eukaryotic ribosome biogenesis. Cell Mol Life Sci 65: 2334-2359.

Ho Y, Gruhler A, Heilbut A, Bader GD, Moore L, Adams SL, Millar A, Taylor P, Bennett K, Boutilier K, et al. 2002. Systematic identification of protein complexes in Saccharomyces cerevisiae by mass spectrometry. Nature 415: 180-183.

Jakel S, Gorlich D. 1998. Importin $\beta$, transportin, RanBP5 and RanBP7 mediate nuclear import of ribosomal proteins in mammalian cells. EMBO J 17: 4491-4502.

Kuhn H, Hierlmeier T, Merl J, Jakob S, Aguissa-Toure AH, Milkereit P, Tschochner H. 2009. The Noc-domain containing C-terminus of Noc4p mediates both formation of the Noc4p-Nop14p submodule and its incorporation into the SSU processome. PLoS ONE 4: e8370. doi: 10.1371/journal.pone.0008370.

Lafontaine DL, Preiss T, Tollervey D. 1998. Yeast 18S rRNA dimethylase Dim1p: a quality control mechanism in ribosome synthesis? Mol Cell Biol 18: 2360-2370.

Milkereit P, Strauss D, Bassler J, Gadal O, Kuhn H, Schutz S, Gas N, Lechner J, Hurt E, Tschochner H. 2003. A Noc complex specif- ically involved in the formation and nuclear export of ribosomal 40 S subunits. J Biol Chem 278: 4072-4081.

Nissan TA, Bassler J, Petfalski E, Tollervey D, Hurt E. 2002. 60S preribosome formation viewed from assembly in the nucleolus until export to the cytoplasm. EMBO J 21: 5539-5547.

Oeffinger M, Dlakic M, Tollervey D. 2004. A pre-ribosome-associated HEAT-repeat protein is required for export of both ribosomal subunits. Genes Dev 18: 196-209.

Pool MR, Stumm J, Fulga TA, Sinning I, Dobberstein B. 2002. Distinct modes of signal recognition particle interaction with the ribosome. Science 297: 1345-1348.

Rickards B, Flint SJ, Cole MD, LeRoy G. 2007. Nucleolin is required for RNA polymerase I transcription in vivo. Mol Cell Biol 27: 937948.

Rigaut G, Shevchenko A, Rutz B, Wilm M, Mann M, Seraphin B. 1999. A generic protein purification method for protein complex characterization and proteome exploration. Nat Biotechnol 17: 1030-1032.

Roger B, Moisand A, Amalric F, Bouvet P. 2003. Nucleolin provides a link between RNA polymerase I transcription and pre-ribosome assembly. Chromosoma 111: 399-407.

Rouquette J, Choesmel V, Gleizes PE. 2005. Nuclear export and cytoplasmic processing of precursors to the $40 \mathrm{~S}$ ribosomal subunits in mammalian cells. EMBO J 24: 2862-2872.

Saveanu C, Bienvenu D, Namane A, Gleizes PE, Gas N, Jacquier A, Fromont-Racine M. 2001. Nog2p, a putative GTPase associated with pre-60S subunits and required for late $60 \mathrm{~S}$ maturation steps. EMBO J 20: 6475-6484.

Schafer T, Strauss D, Petfalski E, Tollervey D, Hurt E. 2003. The path from nucleolar $90 \mathrm{~S}$ to cytoplasmic $40 \mathrm{~S}$ pre-ribosomes. EMBO J 22: $1370-1380$

Sengupta J, Nilsson J, Gursky R, Spahn CM, Nissen P, Frank J. 2004. Identification of the versatile scaffold protein RACK1 on the eukaryotic ribosome by cryo-EM. Nat Struct Mol Biol 11: 957-962.

Tschochner H, Hurt E. 2003. Pre-ribosomes on the road from the nucleolus to the cytoplasm. Trends Cell Biol 13: 255-263.

Turner AJ, Knox AA, Prieto JL, McStay B, Watkins NJ. 2009. A novel small-subunit processome assembly intermediate that contains the U3 snoRNP, nucleolin, RRP5, and DBP4. Mol Cell Biol 29: 30073017.

van de Wetering M, Oving I, Muncan V, Pon Fong MT, Brantjes H, van Leenen D, Holstege FC, Brummelkamp TR, Agami R, Clevers H. 2003. Specific inhibition of gene expression using a stably integrated, inducible small-interfering-RNA vector. EMBO Rep 4: 609-615.

Yanagida M, Shimamoto A, Nishikawa K, Furuichi Y, Isobe T, Takahashi N. 2001. Isolation and proteomic characterization of the major proteins of the nucleolin-binding ribonucleoprotein complexes. Proteomics 1: 1390-1404.

Zemp I, Kutay U. 2007. Nuclear export and cytoplasmic maturation of ribosomal subunits. FEBS Lett 581: 2783-2793.

Zemp I, Wild T, O’Donohue MF, Wandrey F, Widmann B, Gleizes PE, Kutay U. 2009. Distinct cytoplasmic maturation steps of $40 \mathrm{~S}$ ribosomal subunit precursors require hRio2. J Cell Biol 185: 11671180 . 

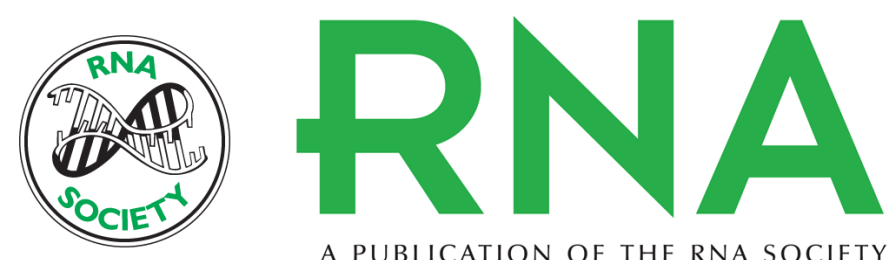

A PUBLICATION OF THE RNA SOCIETY

\section{Tandem affinity purification combined with inducible shRNA expression as a tool to study the maturation of macromolecular assemblies}

Emanuel Wyler, Mirjam Zimmermann, Barbara Widmann, et al.

RNA 2011 17: 189-200 originally published online November 19, 2010 Access the most recent version at doi:10.1261/rna.2325911

Supplemental Material

References

License

Email Alerting Service
http://rnajournal.cshlp.org/content/suppl/2010/11/10/rna.2325911.DC1

This article cites 36 articles, 18 of which can be accessed free at: http://rnajournal.cshlp.org/content/17/1/189.full.html\#ref-list-1

Receive free email alerts when new articles cite this article - sign up in the box at the top right corner of the article or click here.

To subscribe to RNA go to:

http://rnajournal.cshlp.org/subscriptions 